\title{
Organizational Culture Associated With Provider Satisfaction
}

\author{
Debra L. Scammon, PhD, Jennifer Tabler, MS, Kimberly Brunisholz, MST, \\ Lisa H. Gren, PhD, Jaewhan Kim, PhD, Andrada Tomoaia-Cotisel, MPH, MHA, \\ Julie Day, MD, Timothy W. Farrell, MD, Norman J. Waitzman, PhD, \\ and Michael K. Magill, MD
}

Background: Organizational culture is key to the successful implementation of major improvement strategies. Transformation to a patient-centered medical home (PCHM) is such an improvement strategy, requiring a shift from provider-centric care to team-based care. Because this shift may impact provider satisfaction, it is important to understand the relationship between provider satisfaction and organizational culture, specifically in the context of practices that have transformed to a PCMH model.

Methods: This was a cross-sectional study of surveys conducted in 2011 among providers and staff in 10 primary care clinics implementing their version of a PCMH: Care by Design. Measures included the Organizational Culture Assessment Instrument and the American Medical Group Association provider satisfaction survey.

Results: Providers were most satisfied with quality of care (mean, 4.14; scale of 1-5) and interactions with patients (mean, 4.12) and were least satisfied with time spent working (mean, 3.47), paperwork (mean, 3.45), and compensation (mean, 3.35). Culture profiles differed across clinics, with family/clan and hierarchical cultures the most common. Significant correlations $(P \leq .05)$ between provider satisfaction and clinic culture archetypes included family/clan culture negatively correlated with administrative work; entrepreneurial culture positively correlated with the Time Spent Working dimension; market/rational culture positively correlated with how practices were facing economic and strategic challenges; and hierarchical culture negatively correlated with the Relationships with Staff and Resource dimensions.

Conclusions: Provider satisfaction is an important metric for assessing experiences with features of a PCMH model. Identification of clinic-specific culture archetypes and archetype associations with provider satisfaction can help inform practice redesign. Attention to effective methods for changing organizational culture is recommended. ( $\mathrm{J}$ Am Board Fam Med 2014;27:219-228.)

Keywords: Cross-Sectional Studies, Medical Home, Organizational Culture, Patient-Centered Care, Practice Management, Problem Solving

In the management literature, it is widely accepted that an understanding of organization culture is key to the successful implementation of major improvement strategies as well as adaptation to the increas-

This article was externally peer reviewed.

Submitted 14 December 2012; revised 11 October 2013; accepted 15 October 2013.

From the Department of Marketing, David Eccles School of Business (DLS); the Department of Family and Preventive Medicine, School of Medicine (DLS, KB, LHG, JK, AT-C, TWF, MKM); the Department of Sociology (JT); the Division of Geriatrics (TWF); and the Department of Economics, College of Social and Behavioral Science (NJW), University of Utah, Salt Lake City; the Department of Health Services Research and Policy, London School of Hygiene \& Tropical Medicine, London, England (AT-C); Community Clinics, University of Utah Hospitals and Clinics (JD); VA Salt Lake City Geriatric Research, Education, ingly turbulent environment faced by modern organizations. ${ }^{1}$ Health services researchers have investigated the relationship between organiza-

and Clinical Center, Salt Lake City, UT (TWF); and University of Utah HealthPlans, Murray, UT (MKM).

Funding: This project was supported by grant nos. 1 R18 HS019136-02 and R18HS0201-06 from the Agency for Healthcare Research and Quality (to MKM) and by grant no. 1KM1CA156723 from the National Institutes of Health (to JK).

Conflict of interest: none declared.

Disclaimer: The content is solely the responsibility of the authors and does not necessarily represent the official views of the Agency for Healthcare Research and Quality or the National Institutes of Health.

Corresponding author: Debra L. Scammon, PhD, David Eccles School of Business, University of Utah, 1655 Campus Center Dr., Salt Lake City, UT 84112 (E-mail: debra.scammon@ business.utah.edu). 
tional culture and various dimensions of performance. In a review of studies reported in the health care literature, Scott et $\mathrm{al}^{2}$ conclude that "there is some evidence to suggest that organizational culture may be a relevant factor in health care performance, yet articulating the nature of that relationship proves difficult." Nembhard and colleagues ${ }^{3}$ recently argued that as medical groups adapt to changes under health care reform, their success likely depends on their cultures. Thus, a better understanding of the relationship between organizational culture and performance is needed.

Beyond the influence organizational culture may have on practice performance, it can also affect provider satisfaction. In a qualitative study of physicians working in group practice settings, Williams and colleagues ${ }^{4}$ found that organizational culture was an important determinant of physician job satisfaction. Zazzali et $\mathrm{al}^{5}$ found that dimensions of practice culture were associated with individual provider satisfaction with group practice and that these dimensions varied across different cultures. Brazil et $\mathrm{al}^{6}$ found that clinicians reported different levels of job satisfaction and perceived effectiveness depending on the culture of the organization within which they practiced.

Despite this general association between organizational culture and provider satisfaction, little is known about the relationship between practice culture and provider satisfaction with specific features of a patient-centered medical home (PCMH) model. The PCMH model requires a shift from provider-centric care to team-based care. Some providers may be uncomfortable sharing decision making with other members of the care team, in particular with sharing decisions regarding preventive and chronic care. ${ }^{7}$ The focus of PCMHs on comprehensive care and continuity of the providerpatient relationship calls for practices to implement or enhance existing electronic medical record (EMR) systems. Such technological changes may be accompanied by the need to acquire new skills and may trigger resistance or dissatisfaction among some employees. ${ }^{8}$ There is evidence that, with sufficient staffing and practice support, adoption of the PCMH can lead to greater work satisfaction. ${ }^{9}$ Assessment of work-related clinician satisfaction should be among the outcomes measured as practice transformation proceeds. ${ }^{10}$

In the context of the transformation of a practice toward a PCMH, it is critical to consider provider satisfaction with specific aspects of the redesigned care delivery model, including assessment of satisfaction with new approaches to care (team-based, patient-centered care); use of new technologies to support care (EMRs, best practice reminders); and implementation of new compensation plans (performance incentives for dimensions of PCMHs). It is also important to assess the ways in which organizational culture may be differentially associated with specific aspects of providers' experiences in redesigned practices.

In this exploratory study, our objectives were to (1) assess provider satisfaction with specific elements of a PCMH care model; (2) assess the culture of practices that have implemented a $\mathrm{PCMH}$ model, and (3) investigate whether there are associations between clinic culture and specific elements of provider satisfaction with $\mathrm{PCMH}$ features. Further study of the relationship of organizational culture to provider satisfaction will provide insights into how culture may color providers' experiences of - and thus their satisfaction with-particular elements of redesigned practice. It also will help identify ways in which management can facilitate practice redesign while simultaneously enhancing provider satisfaction.

\section{Methods \\ Study Setting}

The University of Utah Community Clinics (CC) is a network of 10 primary care clinics owned by University of Utah Health Care and located in and around Salt Lake City, UT. In the 2011study period, CC employed approximately 70 primary care providers and 170 staff who were directly involved in patient care. Clinics ranged in size from 4 to 12 primary care providers. CC has implemented a care delivery model called Care by Design (CBD). CBD includes many of the components of the $\mathrm{PCMH}$ mode $^{11}$ and was built around 3 organizing principles: appropriate access, care teams, and planned care.

Implementing the $3 \mathrm{CBD}$ principles required many complex and interrelated changes. Appropriate access was introduced in 2003 as a way to balance visit supply and demand. It required the standardization of provider schedules and centralization of appointment scheduling and response to messages. Care teams were implemented in 2004. The physician-led teams included providers and 
medical assistants (MAs) working in tandem and being supported by EMR tools. The MA role was expanded to include recording patients' histories using EMR templates, reviewing medications, obtaining a limited set of radiographs, drawing labs, arranging referrals, and providing immunizations. The implementation of care teams required a shift in focus from provider-centric to team-oriented care. Planned care was initiated in 2006 and included the use of care protocols, order sets, previsit planning, laboratory tests before visits, and registries to support outreach to patients with chronic conditions.

\section{Organizational Culture}

Organizational culture is a term used to describe the values and beliefs held in common by members of an organization. It is stable, socially constructed, and subconscious. ${ }^{12}$ The Competing Values Framework has been widely used in health services research to assess organizational culture. ${ }^{13}$ This framework suggests that organizations can be characterized along 2 dimensions representing alternative approaches that organizations can use to resolve challenges in their everyday functioning; thus they are viewed as "competing." The first dimension is the degree to which an organization emphasizes centralization and control over organizational processes versus decentralization and flexibility. The second dimension is the degree to which the organization is oriented toward its own internal environment and processes versus the external environment and relationships with outside entities. Combining these 2 dimensions creates 4 archetypal cultures, referred to as family/clan, entrepreneurial, market/rational, and hierarchical cultures, as outlined in Figure 1.

Each of these culture archetypes may be compatible with different aspects of a PCMH model. For example, a family/clan culture, with its emphasis on employee empowerment and involvement, may be particularly suited to team-based care. A hierarchical culture, with its emphasis on policies, coordination, and efficiency, may be helpful in larger organizations aiming for standardized practices. A market/rational culture, which is more externally focused, may be appropriate in competitive environments where differentiation between practices is important to market leadership.

\section{Study Design}

As part of a larger project assessing the experience of the CC in implementing CBD, CC primary care providers (ie, internal medicine, family medicine, pediatrics, obstetrics/gynecology, and internal medicine/pediatrics) and staff who support these providers participated in a survey that included the Organizational Culture Assessment Instrument (OCAI). ${ }^{14}$ This survey was distributed during provider and staff meetings at each clinic during the spring of 2011. In a separate survey, conducted in the summer of 2011, the American Medical Group Association's (AMGA) provider satisfaction survey was used to capture physician sentiments. Responses to these 2 surveys were combined for clinic-level analyses of provider satisfaction and clinic culture.

Figure 1. Description of the 4 culture archetypes within the Competing Values Framework for Organizational Culture. Adapted from Cameron and Quinn. ${ }^{1}$

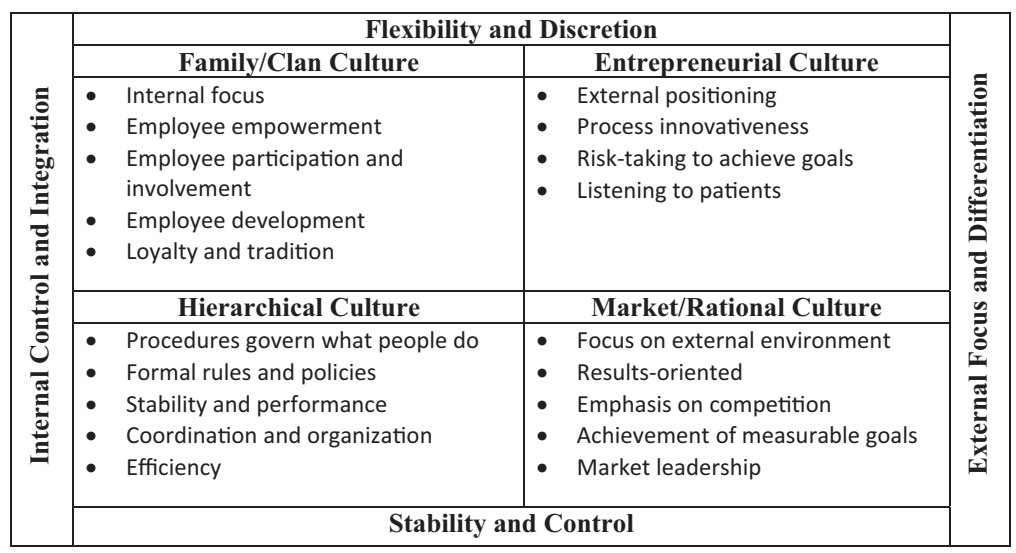




\section{Provider Satisfaction Survey}

The AMGA provider satisfaction survey includes 55 questions structured to assess 12 dimensions of practice life. ${ }^{15}$ The reliability and validity of this instrument have been well established. ${ }^{16}$ All CC physicians were asked to complete the survey. To ensure that their responses are kept anonymous, physicians' responses were reported to the CC only in aggregate for all physicians practicing at each clinic and only for clinics with $\geq 4$ physicians responding. We had access to clinic-level data for 9 of our 10 clinics.

Our CBD model was intended to enhance quality of care, clinic efficiency, and clinic productivity as well as physician satisfaction with aspects of their work life. The AMGA provider satisfaction survey includes items that assess activities and outcomes related to CBD, such as providers' satisfaction with "time spent working," "control over schedule," and "relationships with patients."

\section{Organizational Culture Assessment Instrument}

To assess organizational culture, we used the OCAI ${ }^{14}$ which is based on the Competing Values Framework. As mentioned earlier, it identifies 4 organizational archetypes: family/clan, entrepreneurial, market/rational, and hierarchical. The OCAI is structured into 6 domains: organizational character, managers and leadership, organizational cohesion, management of employees, organizational emphases, and criteria for success. ${ }^{14}$ Our survey used an ipsative scale, with participants relating their own clinic's culture to the archetypes by distributing 100 points among the 4 archetypes in each of the 6 domains. Use of an ipsative scale forces respondents to make trade-offs among the archetypes they perceive within their organization; thus archetype scores are not independent. The OCAI has been widely used across many industries, and its reliability and validity have been shown to be acceptable. ${ }^{1}$ The study was approved by the University of Utah's institutional review board.

\section{Statistical Analysis}

Determining Provider Satisfaction Scores for Each Clinic

Provider satisfaction data for each clinic were obtained from a CC report of provider responses at the clinic level. Responses are reported on 5-point scales from "very dissatisfied" (1) to "very satisfied" (5). Satisfaction dimension scores were calculated for 12 dimensions of practice by combining the clinic-level satisfaction items relevant to each dimension and generating an overall mean dimension score. All analyses of the provider satisfaction data were performed at the clinic level.

\section{Determining Clinic Culture Profiles}

Clinic culture archetype scores were determined using individual-level responses from providers and staff at each clinic. Clinic-level culture profiles included scores for each of the 4 archetypes and were calculated by averaging the scores for each participant within each clinic for each archetype. Mean archetype scores were compared across the clinics using analysis of variance followed by Tukey pairwise comparisons of archetype means.

\section{Correlation Analysis}

We used clinic-level data for both provider satisfaction and culture profiles to evaluate the relationship between clinic-level satisfaction scores (individual items and dimensions) and each clinic's culture archetype profile (all four archetypes). We used Spearman correlation to evaluate these relationships.

\section{Results}

\section{Provider Satisfaction}

Completed satisfaction surveys were reported for 63 providers from the 9 included clinics, representing an overall response rate of $94 \%$. Response rates ranged from $80 \%$ to $100 \%$ across the clinics. Across all the clinics, the dimensions with which providers were most satisfied were computers (mean, 4.68), followed by acceptance by colleagues (mean, 4.22), quality of care provided (mean, 4.14), and patient interactions (mean, 4.12). Dimensions with which providers were least satisfied included the preauthorization process (mean, 3.15), compensation (mean, 3.35), paperwork (mean, 3.45), and time spent working (mean, 3.47) (see Table 1).

\section{Clinic Culture Profiles}

OCAI surveys completed by providers/staff were received from 162 respondents, representing an overall response rate of $75 \%$, with a range across individual clinics of $48 \%$ to $100 \%$. For analysis, 28 surveys were excluded (15 from providers and 13 from staff) because of missing data or respondents not following instructions, leaving 134 completed 


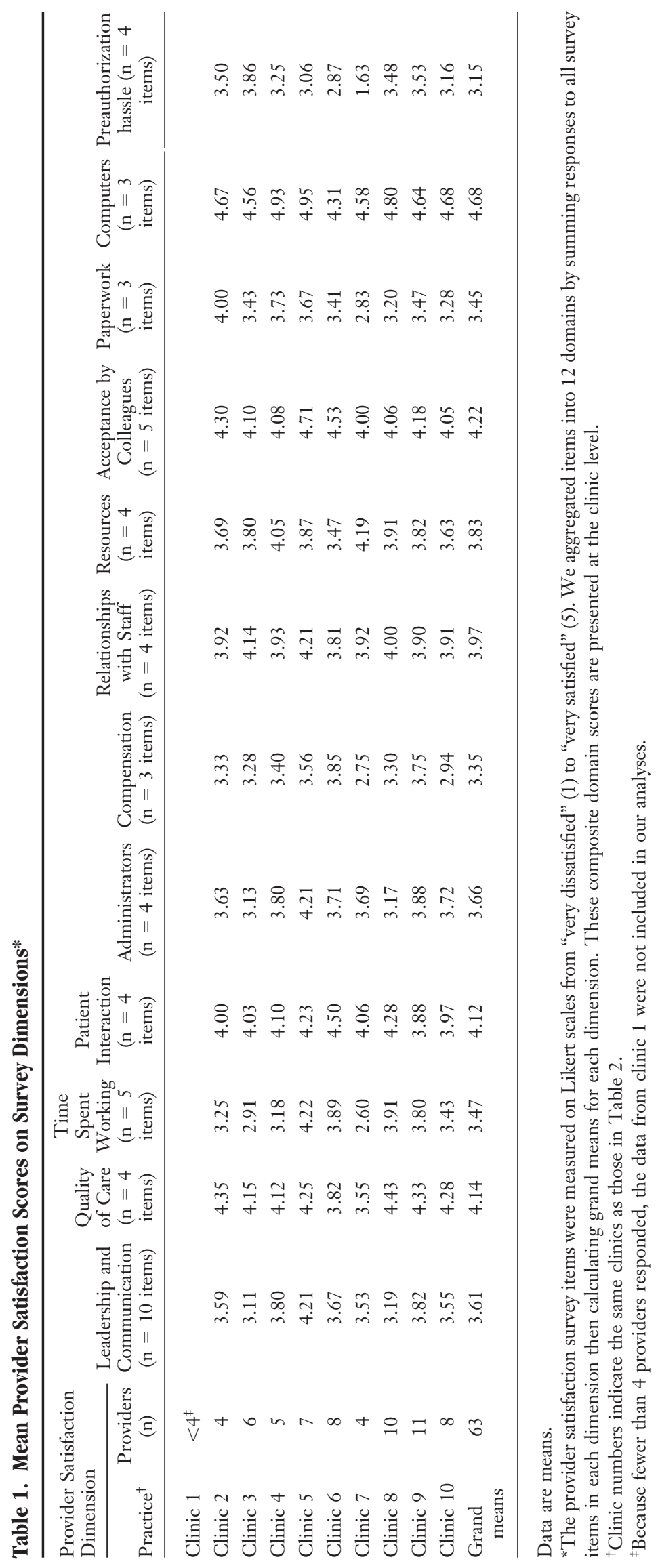


surveys. Of the remaining respondents, 20.2\% were providers and $79.8 \%$ were MAs. Providers and staff reported similar perceptions of their team's culture; responses of providers and staff differed on only 2 of the 24 OCAI items, as determined using the $t$ test $(P \leq .05)$. Thus their responses were combined for analysis.

The mean scores and standard deviations for each of the archetypes for each clinic are presented in Table 2. Among the 10 clinics, the highest archetype score for 4 clinics was family/clan, for 4 clinics it was hierarchical, and for 2 clinics it was market/rational; none of our clinics had entrepreneurial as the highest archetype score. Across all 10 clinics, mean scores for the culture archetypes were 30.1 for family/clan, 15.4 for entrepreneurial, 24.2 for market/rational, and 30.3 for hierarchical. The culture profiles for all the clinics are portrayed in Figure 2.

\section{Association of Provider Satisfaction and Organizational Culture}

Using the full culture profile for individual clinics, we ran Spearman correlations with the clinic-level provider satisfaction scores on the 12 satisfaction dimensions. To help us interpret the domain correlations, we also conducted correlation analyses between culture profiles and individual satisfaction items. As noted, data for only 9 of 10 clinics were available for these analyses. A number of correlations between culture archetypes and provider satisfaction were significant at $P \leq .05$. Patterns of correlation were quite different for each of the 4 archetypes (see Table 3).

The family/clan archetype was not correlated with any of the provider satisfaction dimensions. It was, however, negatively correlated with the survey item about the amount of administrative work required $(P=.025)$. The entrepreneurial archetype was positively correlated with the time spent working dimension $(P=.013)$. This was driven by positive correlations with 2 items within that dimension: degree of control over providers' schedule $(P=.008)$ and amount of time spent with each patient $(P=.005)$. The market/rational archetype was positively correlated with one dimension of provider satisfaction and 2 survey items. These included the quality of care dimension $(P=.030)$ and survey items from the leadership and communication dimension (how well the group is facing economic and strategic challenges; $P=.030$ ) and the paperwork dimension (administrative work; $P=$.002). The hierarchical archetype was negatively correlated with the relationships with staff $(P=.024)$ and resources dimensions $(P=.025)$.

\section{Discussion}

Our study provides a novel contribution to the literature on health care redesign. We examined provider satisfaction, organizational culture, and their correlation within our network of primary care clinics that has implemented a PCMH model. Here we summarize and interpret our key findings.

Table 2. Culture Archetype Scores Within the Community Clinics

\begin{tabular}{|c|c|c|c|c|c|}
\hline \multirow[b]{2}{*}{ Community Clinics (respondents) } & \multicolumn{4}{|c|}{ Culture Archetypes } & \multirow[b]{2}{*}{$P$ Value } \\
\hline & Family/Clan & Entrepreneurial & Market/Rational & Hierarchical & \\
\hline Overall mean $(\mathrm{n}=10$ clinics $)$ & $30.1(16.3)$ & $15.4(9.8)$ & $24.2(13.6)$ & $30.3(11.9)$ & .001 \\
\hline Clinic $1(n=10)$ & $28.8(17.2)$ & $11.9(8.3)$ & $23.5(15.7)$ & $35.8(15.5)$ & .007 \\
\hline Clinic $2(n=15)$ & $25.5(15.7)$ & $18.4(10.0)$ & $29.4(17.5)$ & $26.6(12.4)$ & .170 \\
\hline Clinic $3(n=16)$ & $37.3(10.0)$ & $14.8(9.7)$ & $18.4(7.6)$ & $29.5(12.6)$ & $<.001$ \\
\hline Clinic $4(n=13)$ & $44.7(18.4)$ & $10.1(11.2)$ & $16.5(9.9)$ & $28.7(12.8)$ & $<.001$ \\
\hline Clinic $5(\mathrm{n}=10)$ & $19.2(10.2)$ & $10.2(7.8)$ & $33.7(16.5)$ & $36.9(10.4)$ & .002 \\
\hline Clinic $6(n=25)$ & $28.8(15.4)$ & $14.2(9.2)$ & $22.7(14.7)$ & $34.2(12.0)$ & $<.001$ \\
\hline Clinic $7(n=12)$ & $22.1(12.1)$ & $15.5(9.2)$ & $27.5(10.3)$ & $34.8(13.5)$ & .003 \\
\hline Clinic $8(n=11)$ & $25.2(13.9)$ & $14.5(8.8)$ & $31.1(15.2)$ & $29.3(6.2)$ & .008 \\
\hline Clinic $9(\mathrm{n}=9)$ & $32.1(20.9)$ & $15.4(10.0)$ & $21.5(11.2)$ & $31.0(11.4)$ & .056 \\
\hline Clinic $10(n=13)$ & $32.4(9.5)$ & $17.6(5.7)$ & $24.3(11.6)$ & $25.7(5.0)$ & .001 \\
\hline
\end{tabular}

Data are mean (SD). Bold values indicate the highest archetype score for each clinic.

*Analysis of variance of mean archetype scores across clinics followed by Tukey's pairwise comparison of archetypes within clinic (data not shown). 
Figure 2. The organizational culture profiles of the 10 community clinics. Each colored trapezoid represents a single clinic.

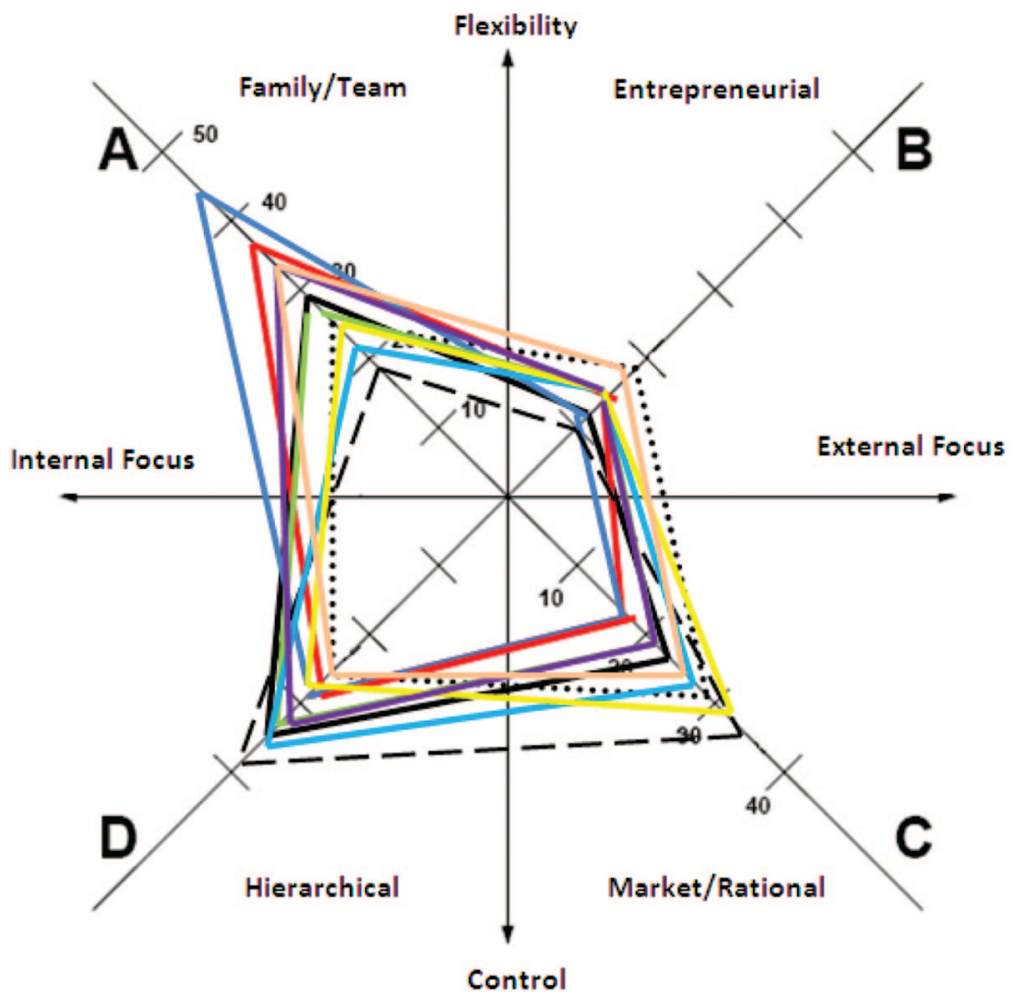

\section{Provider Satisfaction}

Our analyses of the dimensions included in the provider satisfaction survey suggest that, as intended with the implementation of our CBD model, providers are generally satisfied with the quality of care provided and patient interactions dimensions. In addition, they are satisfied with the acceptance by colleagues and computers dimensions, which is consistent with findings elsewhere. ${ }^{9}$ When supported by adequate resources (eg, EMRs and colleagues also participating in practice change), practicing in a PCMH model can be satisfying.

Providers were least satisfied with the time they spend working, the paperwork required, the preauthorization process, and compensation. Many of the process and paperwork requirements with which providers are dissatisfied result from external demands such as those of payers. Requirements that involve additional work for which providers cannot bill likely contribute to their dissatisfaction with compensation. Dissatisfaction with the compensation dimension may also reflect the tension between productivity and quality in a fee-for-service environment. ${ }^{17,18}$

\section{Clinic Culture}

Although our clinics are all affiliated with the same university-owned network, we found differences in culture archetype profiles among our clinics. Within our network, family/clan and hierarchical cultures were the most prevalent. Other research has found that primary care practices commonly have family/ clan cultures. ${ }^{6}$ Four of our clinics have high hierarchical archetype scores. Three of these clinics were also high on another archetype, either market/rational or family/clan, suggesting that multiple cultures can coexist within an individual clinic. ${ }^{3}$

Our findings highlight the importance of assessing, rather than assuming, knowledge of organizational culture. The propensity of practices with different culture archetypes to implement changes necessary to become PCMHs may be quite different. Recognition of the differences between culture archetypes can be helpful to management in fostering practice redesign.

\section{Association Between Clinic Culture and Provider Satisfaction}

We found a negative correlation between the family/clan culture archetype and providers' satisfac- 
Table 3. Spearman Correlation of Provider Satisfaction With Clinic Culture Archetypes

\begin{tabular}{|c|c|c|c|c|}
\hline \multirow[b]{2}{*}{ Dimension/Survey Items by Provider Satisfaction } & \multicolumn{4}{|c|}{ Culture Archetypes } \\
\hline & Family/Clan & Entrepreneurial & Market/Rational & Hierarchical \\
\hline \multicolumn{5}{|l|}{$\begin{array}{l}\text { Leadership and communication dimension }(\mathrm{n}= \\
\qquad 10 \text { items) }\end{array}$} \\
\hline \multicolumn{5}{|l|}{$\begin{array}{l}\text { How well your group is facing the economic and } \\
\text { strategic challenges confronting the physicians } \\
\text { in this country }\end{array}$} \\
\hline Coefficient & -0.550 & 0.067 & 0.717 & 0.017 \\
\hline$P$ value & .125 & .865 & $.030^{*}$ & .966 \\
\hline \multicolumn{5}{|l|}{$\begin{array}{l}\text { Quality of care you are able to provide dimension } \\
\qquad(\mathrm{n}=4 \text { items })\end{array}$} \\
\hline Coefficient & -0.500 & 0.283 & 0.717 & -0.083 \\
\hline$P$ value & .171 & .460 & $.030^{*}$ & .831 \\
\hline \multicolumn{5}{|l|}{ Time spent working dimension $(\mathrm{n}=5$ items $)$} \\
\hline Coefficient & -0.300 & 0.783 & 0.367 & -0.183 \\
\hline$P$ value & .433 & $.013^{*}$ & .332 & .637 \\
\hline \multicolumn{5}{|l|}{ Degree of control you have over your schedule } \\
\hline Coefficient & 0.050 & 0.812 & 0.034 & -0.385 \\
\hline$P$ value & .898 & $.008^{\dagger}$ & .932 & .306 \\
\hline \multicolumn{5}{|l|}{ Amount of time you spend with each patient } \\
\hline Coefficient & -0.400 & 0.833 & 0.383 & -0.017 \\
\hline$P$ value & 0.286 & $0.005^{\dagger}$ & 0.309 & 0.966 \\
\hline \multicolumn{5}{|l|}{ Relationships with staff dimension ( $\mathrm{n}=4$ items) } \\
\hline Coefficient & 0.385 & 0.310 & 0.017 & -0.736 \\
\hline$P$ value & .306 & .418 & .966 & $.0245^{*}$ \\
\hline \multicolumn{5}{|l|}{ Resources dimension ( $n=4$ items) } \\
\hline Coefficient & 0.400 & -0.217 & -0.100 & -0.733 \\
\hline$P$ value & .286 & .576 & .798 & $.025^{*}$ \\
\hline \multicolumn{5}{|l|}{$\begin{array}{l}\text { Acceptance by colleagues dimension }(n=5 \\
\text { items) }\end{array}$} \\
\hline \multicolumn{5}{|l|}{$\begin{array}{l}\text { My values are consistent with those of my } \\
\text { colleagues. }\end{array}$} \\
\hline Coefficient & -0.233 & 0.667 & 0.200 & 0.017 \\
\hline$P$ value & .546 & $.050^{*}$ & .606 & .966 \\
\hline \multicolumn{5}{|l|}{ Paperwork dimension ( $\mathrm{n}=3$ items) } \\
\hline \multicolumn{5}{|l|}{ I do not have too much administrative work to do. } \\
\hline Coefficient & -0.733 & 0.233 & 0.883 & 0.150 \\
\hline$P$ value & $.025^{*}$ & .546 & $.002^{\dagger}$ & .700 \\
\hline
\end{tabular}

Because of the small sample size, we conducted nonasymptotic Spearman's rank correlations rather than Pearson's correlations. ${ }^{*} P \leq .05$.

${ }^{\dagger} P \leq .01$.

tion with the amount of administrative work they have to do. There are several factors that may be driving this correlation, including the size of the patient panel and new work that is required for patient-centered care. ${ }^{17}$ The delivery of patientcentered care with a focus on continuity of information and coordination of care requires the development of relationships outside the practice. Relationship building and information exchange are new tasks that must be assumed by members of the care team, and this extra work may result in tensions among team members, especially when the patient-to-provider ratio is high. Practice change within family/clan cultures may be facilitated by stressing the accountability of all members of the team in the implementation of new processes. Clear definitions of roles and explanations of the rationale for new procedures may facilitate transformation.

The entrepreneurial culture archetype was positively associated with providers' satisfaction with the time spent working dimension, including pro- 
viders' sense of control over their schedules and the time they spend with each patient. In entrepreneurial cultures, where flexibility is highly valued, it is important to sustain providers' ability to modify their schedules as needed to accommodate their patients' needs and a practice's ability to respond to external factors such as perceived competition and patient demand.

The market/rational culture was positively associated with provider satisfaction with the quality of care dimension and with leadership in facing economic and strategic challenges. A market/rational culture emphasizes achieving competitive advantage. The pattern of provider satisfaction observed in clinics with strong market/rational cultures may reflect recognition that practice redesign facilitates the delivery of quality care, thus enhancing the ability of a practice to respond to local market forces.

The hierarchical archetype was negatively correlated with 2 dimensions of provider satisfaction: relationships with staff $(P=.024)$ and resources $(P=.025)$. In hierarchical cultures, managers should be aware of the potential for dissatisfaction surrounding staff relationships and resources as transformation occurs.

Our finding that providers' experience of and satisfaction with features of a PCMH model of care are associated with organizational culture suggests that understanding the relationship between organizational culture and provider satisfaction may be helpful for management in facilitating clinic transformation into PCMH models. With knowledge of the cultures within individual clinics, managers may be able to adapt both their messages about transformation and their management of the change process to be more compatible with individual clinic's cultures, reducing barriers to change. By identifying existing cultures, management may be able to implement culture change strategies that will facilitate transformation toward a culture more aligned with environmental demands.

\section{Limitations}

Our analyses were limited by the small number of clinics in our network and by our cross-sectional design. With organizational culture data for 10 clinics and provider satisfaction data for only 9 clinics, we relied on simple correlations at the clinic level to detect associations. A study design that includes a larger set of clinics and individual-level data would advance the understanding of these relationships. With our cross-sectional design, it is not possible to assess the dynamics of clinic culture. A longitudinal design examining change in provider satisfaction during a period of delivery model transformation could also provide important insights.

Our analyses reveal relatively few significant correlations between provider satisfaction and clinic culture archetypes. It may be that the AMGA provider satisfaction survey developed before the movement toward a PCMH does not adequately assess aspects of providers' work life that are most affected by the implementation of a PCMH model. It may also be that the OCAI measure of organizational culture, developed outside of health care, does not facilitate the identification of aspects of culture that are particularly relevant to a $\mathrm{PCMH}$, such as a quality orientation or patient-centeredness. The use of survey instruments that more explicitly assess elements of a PCMH and cultural orientations that support the philosophy of the PCMH may identify additional correlations between provider satisfaction and clinic culture.

A clinic's organizational culture both affects and is affected by the providers who practice in a given clinic. It also may reflect aspects of the external environment. The relationship between culture and provider satisfaction is complex, and our results may be affected by self-selection of providers to clinics with cultures in which they feel comfortable.

In examining the relationship of organizational culture to provider satisfaction, we combined survey responses from providers and staff in individual clinics to determine culture archetype scores for each clinic. However, we did not take this clustering into account in our analyses, so we may have underestimated standard errors.

Furthermore, 2 different groups of participants responded to our 2 surveys. A combined group of providers and staff completed the OCAI survey, whereas only providers completed the provider satisfaction survey. It is possible that our correlation results may have been different had we been able to match respondents from the 2 surveys.

Finally, our clinics are part of a universityowned, community-based practice network. As such, their structure is different from that of many clinics, and our specific findings may not be able to be replicated in nonuniversity-owned clinics or in clinics with other organizational affiliations. 


\section{Conclusions}

As health care reform progresses, organizational culture change may be necessary. By identifying existing cultures, management may be able to implement culture-change strategies that will facilitate transformation toward a culture more aligned with environmental demands. For example, previously independent clinics may join accountable care organizations. As these organizations work to deliver high-value care, there will be pressure to eliminate variation in practice. In this context, the internally focused and flexible family/clan culture often found in primary care practices may no longer be appropriate. More externally focused and integrated cultures that emphasize stability and control may be better positioned to meet patients' needs. As redesign occurs, although a more hierarchical culture may be helpful in achieving the goals of larger integrated organizations, management should be alert to ways in which provider-staff relationships can be strengthened, adequate resources can be provided, and quality of care can be enhanced and communicated effectively to external stakeholders. Attention to effective methods for changing organizational culture in a way that enhances provider satisfaction is recommended.

We acknowledge the contribution of Rachel Day, BS, Department of Family and Preventive Medicine, School of Medicine, University of Utah, for assistance in conceptualizing the study.

\section{References}

1. Cameron K, Quinn R. Diagnosing and changing organizational culture: Based on the competing values framework. 3rd Ed. San Francisco (CA): JosseyBass; 2011.

2. Scott T, Mannion R, Marshall M, Davies H. Does ogranisational culture influence health care performance? A review of the evidence. J Health Serv Res Policy 2003;8:105-17.

3. Nembhard IM, Singer SJ, Shortell SM, Rittenhouse D, Casalino LP. The cultural complexity of medical groups. Health Care Manage Rev 2012;37:200-13.

4. Williams ES, Konrad TR, Linzer M, et al. Physician, practice, and patient characteristics related to primary care physician physical and mental health: results from the Physician Worklife Study. Health Serv Res 2002;37:121-43.

5. Zazzali JL, Alexander JA, Shortell SM, Burns LR. Organizational culture and physician satisfaction with dimensions of group practice. Health Serv Res 2007;42(3 Pt 1):1150-76.
6. Brazil K, Wakefield DB, Cloutier MM, Tennen $\mathrm{H}$, Hall CB. Organizational culture predicts job satisfaction and perceived clinical effectiveness in pediatric primary care practices. Health Care Manage Rev 2010;35:365-71.

7. Ghorob A, Bodenheimer T. Sharing the care to improve access to primary care. New Engl J Med 2012;366:1955-7.

8. Jaen CR, Crabtree BF, Palmer RF, et al. Methods for evaluating practice change toward a patient-centered medical home. Ann Fam Med 2010;8(Suppl 1):S920; S92.

9. Reid RJ, Coleman K, Johnson EA, et al. The group health medical home at year two: cost savings, higher patient satisfaction, and less burnout for providers. Health Aff (Millwood) 2010;29:835-43.

10. Altschuler J, Margolius D, Bodenheimer T, Grumbach K. Estimating a reasonable patient panel size for primary care physicians with team-based task delegation. Ann Fam Med 2012;10:396-400.

11. Egger MJ, Day J, Scammon DL, Li Y, Wilson A, Magill MK. Correlation of the Care by Design primary care practice redesign model and the principles of the patient-centered medical home. J Am Board Fam Med 2012;25:216-23.

12. Helfrich CD, Li YF, Mohr DC, Meterko M, Sales AE. Assessing an organizational culture instrument based on the Competing Values Framework: exploratory and confirmatory factor analyses. Implement Sci 2007;2:13.

13. Quinn RE, Rohrbaugh J. A competing values approach to organizational effectiveness. Public Product Rev 1981;5:122-40.

14. Cameron K, Quinn R. Diagnosing and changing organizational culture: based on the competing values framework. Reading (MA): Addison-Wesley; 1999.

15. American Medical Group Association. American Medical Group Association provider satisfaction survey protocol. Available from: http://www.amga.org/PI/SAT/ PROSAT/survey_prosat.asp. Accessed January 20, 2014.

16. Kerr EA, Hays RD, Mittman BS, Siu AL, Leake B, Brook RH. Primary care physicians' satisfaction with quality of care in California capitated medical groups. JAMA 1997;278:308-12.

17. Day J, Scammon DL, Kim J, et al. Quality, satisfaction, and financial efficiency associated with elements of primary care practice transformation: preliminary findings. Ann Fam Med 2013;11(Suppl 1): S50-9.

18. Tomoaia-Cotisel A, Scammon DL, Waitzman NJ, et al. Context matters: the experience of 14 research teams in systematically reporting contextual factors important for practice change. Ann Fam Med 2013; 11(Suppl 1):S115-23. 